\title{
2. Conservation psychology and climate change
}

\section{Susan Clayton}

As the project of this book indicates, the major question surrounding environmental change and degradation is no longer, "Is it happening?", but "What can people do about it?" This is frequently followed by the frustrated question, "Why aren't people doing anything (or doing enough) to address climate change?", or framed more positively, "What explains the people who are taking action?" With this as the foundation, it becomes clear that we need to consider what motivates or deters people from engaging in actions that protect the climate. Only by understanding these positive and negative factors can we create a social context in which barriers are reduced, facilitators are enhanced, and more people act in ways that protect the natural world.

The investigation into behavioral motivations is a fundamentally psychological question. Fortunately, psychologists are increasingly contributing to research and policy that is directed toward environmental challenges. Psychological research on sustainable behavior, examining some of the triggers of actions such as recycling or energy efficiency, has existed more or less since the 1950s. More recently, psychologists have emulated conservation biology by developing the field of conservation psychology: psychological research and theory directed toward understanding and promoting a healthy relationship between humans and the natural world (Clayton \& Myers, 2015).

The relevance of psychology to sustainability is important to examine for what it says about the role of nature in our lives. Psychologists are deeply concerned with human behavior, and with understanding the motivators and facilitators of behavior in order to promote positive behavioral change. But psychologists are also concerned with human health and well-being, and we are beginning to understand the relevance of environmental health to human health. There has been a veritable explosion of research demonstrating not only the threat that climate change poses to human health, but also the positive benefits that can be obtained from exposure to a healthy natural environment. Thus, even for anyone short-sighted enough to claim that they don't care about the health of the environment, there are reasons for concern about environmental degradation. 
Before looking more closely at the barriers and motivators underlying sustainable behavior, I will briefly summarize what research has shown about the significance of the environment to human well-being.

\section{THE INTERDEPENDENCE OF HUMAN AND ENVIRONMENTAL HEALTH}

In the early years of the climate movement, the principal icon was a polar bear on a melting glacier. Indeed, this is still one of the things people most associate with climate change. People were encouraged to empathize with the animals in order to create concern about the climate; there was little sense that self-interest should be enough to motivate people. Those days are past. Weather and climate events such as hurricanes, droughts, and wildfires, in combination with media coverage that at least sometimes links these events to climate change, have led to an increased awareness of human vulnerability. Recent assessment reports from the Intergovernmental Panel on Climate Change (IPCC) have included a section on human health impacts, and this topic will receive even more coverage in the Sixth Assessment Report, due out in 2022.

\section{Health Impacts from Environmental Changes}

Some of the ways in which environmental health affects human health are easy to envision. The contaminants associated with air, land, and water pollution can be absorbed by humans in ways that compromise physical health and sometimes intellectual capabilities. The extreme weather events associated with climate change threaten safety and well-being, both during the event and in the aftermath as people cope with the damage to shelter, the medical system, food and water supplies, and physical infrastructure. Environmental degradation can lead to food insecurity, and environmental changes can lead to the spread of insect-borne diseases such as Lyme disease and Zika.

Other physical threats are less obvious. For example, warmer temperatures, such as those accompanying climate change, are associated with increased ground-level ozone, a toxic air pollutant. Climate change is leading to more severe asthma and allergic reactions. When environmental changes make a place less suitable for human habitation, environmental migration results, putting the migrants at increased risk to physical safety not only during the migration itself but also, frequently, when they arrive at a new location, where they may not be welcomed by local inhabitants.

Even less attention is paid to the potential impacts of environmental changes on mental health. As with the physical impacts, some of these are fairly easy to recognize. Experiencing extreme weather events such as hurricanes, floods, or wildfires increases the risk of serious mental health problems such 
as post-traumatic stress disorder or depression. Drought has been linked to a significant increase in suicide, especially among farmers. More recently, accumulating evidence has connected a rise in temperature to increases in aggression, suicide, and mental health problems. Air pollution is also associated with psychological distress.

Some reporters, researchers, and therapists have begun to speculate about a more general threat to mental health associated with the perception of changes in the environment, using terms such as "eco-anxiety", "solastalgia", and "climate change distress". It is still too early to definitively characterize this response, but there is growing evidence that people are worried about environmental changes and that environmental degradation is a source of stress, anxiety, and sadness for many.

\section{Positive Impacts of Nature}

It is important, however, to also acknowledge the potential for the environment to positively affect people's health and well-being. Researchers have been investigating this topic for decades, but are becoming increasingly confident in the link between health and exposure to "green" or "blue" spaces (i.e., vegetation and water). Results from both correlational studies and controlled experiments have shown that exposure to green spaces can reduce stress, lower heart rate and blood pressure, lead to faster recovery from illness, and contribute to longevity. Cognitive performance and work productivity tend to be enhanced by the presence of green plants or a view of nature. People who live near green space have better physical and mental health. Thus, even for the few people who do not value nature, or for the larger percentage who prioritize human well-being over environmental well-being, there is a sufficient reason for taking action to protect and preserve a healthy environment.

\section{BARRIERS TO ACTION}

Given the powerful arguments in favor of environmental protection, why is it that so many fail to take action, and continue to behave in ways that contribute to environmental degradation? In addressing this question, we should first acknowledge that all of us - certainly all of us in the developed world - are participants in the problem. Even those of us who are trying to do the right thing are using fossil fuels and other non-renewable environmental resources, contributing to the loss of habitat for wild species, and contaminating the air, land, or water. This is to say that none of us can speak from a position of virtue from which we can point fingers at others who are acting badly. There are many fundamental barriers that, to a greater or lesser extent, inhibit all of us from behaving sustainably. Some of these are structural rather than psychological: 
we may not have the means to act in the ways that we prefer. If I have to get to work and there is no public transportation, I will need to drive a car. At other times, people may simply not know that their behavior is problematic, or they may be unaware that there are behavioral alternatives. Or they may be aware of the problem, but not know how to engage in actions that help to address it.

In addition to inability and ignorance, a third powerful inhibitor of positive behavior needs to be recognized: inattention. In a vast proportion of the time, people take action without really thinking about what they are doing. They act out of habit, or by mimicking what other people are doing. They are not consciously considering the pros and cons of their behavioral choices. All of us are so caught up in the trivia of daily living that we may not stop to think about the larger questions and opportunities to behave in more meaningful ways.

These barriers occur before people even start to think about environmental issues. But I want to examine the reasons why, when people are aware of the possibility that their behavior has implications for environmental well-being, they still make the less sustainable choice. There are many obstacles standing in the way of sustainable action. I will describe them according to three categories: cognitive barriers, which make it difficult to think clearly about environmental problems such as climate change; emotional barriers, in which feelings about the topic inhibit a person from confronting it; and social barriers, in which one's relationships with other people interfere with the ability to respond effectively to the problems.

\section{Cognitive Barriers}

Our brains are not well equipped for thinking about environmental problems. We evolved in a context in which the problems we had to deal with were concrete and short term: finding food and shelter, mating, defending ourselves from adversaries. People didn't live long enough to worry about long-term problems, and this tendency to disregard the future still defines us today. Many if not most people put their long-term health at risk through poor eating habits, lack of exercise, and overindulgence in risky substances or behavior. They fail to set aside enough money for retirement, even when it is within their capability. They make decisions that ignore future consequences. Environmental problems mostly unfold slowly, so that the impacts are not likely to emerge for decades. When it comes to threats such as these, many people are inclined to put off addressing it, "think about that tomorrow", and hope that something happens - some new invention, perhaps - that will eliminate the need to respond to the problem.

Environmental problems are also complex. People find it easiest to understand causal relationships when the effect is not only close in time to the cause, but also at a similar scale and type. The elaborate networks that underlie the 
connection between driving a car, or eating meat, and consequences such as increased global temperatures or the extinction of species, are beyond the comprehension of many. The fact that cold weather can still occur even in the face of general global warming seems impossible for many political figures to understand. Systems thinking is required to fully grasp the connections among processes occurring at different levels and in different domains (behavioral, ecological, geophysical). Even though people may be capable of understanding these connections if they try, they may be too preoccupied with more pressing concerns to devote the cognitive effort.

Negative environmental consequences not only emerge slowly; their nature and timing are also uncertain. We have known about the potential for climate change since at least the 1950s (arguably earlier), but the models that describe the nature, scope, and timing of the impacts have been evolving over that time and are still imperfect. It is still difficult to attribute any single weather event to climate change, and no one can predict exactly how much rainfall will change, or sea level will increase, in a particular location at a specific point in time. This uncertainty makes it possible for people to feel as though "the jury is still out": the existence of climate change is still uncertain. Given a range of possible outcomes, and a poor understanding of probability, people may choose to believe that the outcomes will be minimal, despite the fact that serious outcomes are much more likely. Especially when powerful media and political figures continue to insist that there is no problem, it may seem like a legitimate option to agree with them.

\section{Emotional Barriers}

This brings us to the second set of barriers: emotional responses. The impact of cognitive barriers would not be as significant were it not that people have preferences about what to believe. Environmental problems are scary, and it is unpleasant to think about scary things. One option is merely to avoid thinking about them. Avoidance probably characterizes the response of most reasonably informed people: they know that bad environmental things are happening but manage to go about their lives without paying much attention to the fact. A more extreme option is denial - refusing to believe in things that we would prefer to believe are not true. Denial is a powerful and profound human capability. It allows people to stay functional rather than being paralyzed by fear, but it also prevents them from effectively responding to a problem.

Ironically, although an overly strong emotional response can create one kind of barrier, insufficient concern is another. Some people believe, falsely, that environmental changes do not threaten the things that they care about. Climate change seems psychologically distant to them, something that might affect future generations, polar bears, or even people in far-off countries - but not 
anything that will significantly affect them. For those people, apathy may be the biggest obstacle that is inhibiting them from sustainable behavior.

A third level of emotional barrier is slightly more complex: it is based on the threat to one's ideology or belief system. System justification refers to the need to defend the system by which one lives, which could include capitalism, a Western lifestyle, or a set of religious beliefs. If acknowledging a problem requires that a person deny the beliefs that are important to them, they will be strongly motivated to ignore the problem. So, when people are informed that climate change is caused by their way of life - a lifestyle that they have engaged in without reflection or evil intent, but one characterized by a high carbon footprint due to materialism and heavy use of fossil fuels - they would rather not cope with the guilt, along with the recalibration of their norms and standards that appears to be required. More specifically, people who have a political ideology that embraces capitalism and rejects government intervention may refuse to accept climate change if it appears to be incompatible with that position. Some of the most powerful ideologies are religious. The reality of climate change is seen as inconsistent with religious doctrine by some, who believe that God is in charge of the Earth and nothing that human beings do can interfere with God's plan. Even beyond this, some Christian groups point to the story of the Flood and God's supposed promise to Noah that such an event would never happen again. For these groups, worrying about flooding implies worrying that God would break his promise, something that would be incredible to them.

All three types of emotional barriers - denial, apathy and ideological defense - are illustrated by remarks to the October 2018 Oil and Money Conference by the CEO of Shell Oil. He said: "Shell's core business is and will be for the foreseeable future very much in oil and gas". What is required to keep global warming under $1.5^{\circ} \mathrm{C}$ "can be done in massive reforestation. Think of another Brazil in terms of rainforest". He apparently does not feel worried about the concept of climate change, because it does not seem to him to threaten what he most cares about: his business. Although he seems at some level to acknowledge that climate change is real, he is also engaged in a certain amount of denial, such that he has convinced himself that the problem does not require his company to take action. Finally, his devotion to business as usual is obvious.

\section{Social Barriers}

Some of these examples highlight the relevance of social factors. Ideologies, in particular, are typically associated with groups that define, maintain and encourage standards concerning the specific beliefs each ideology comprises. When a person belongs to a particular religious or political community, there 
may be significant pressure to conform to the group's position on climate change: incredulity, mockery, or shunning of people who dare to state a different position. In the absence of a supporting group, ideologies may crumble, or at least be more prone to redefinition. In general, the social context can promote or activate the barriers already described. Beyond this, however, there are two additional barriers, particularly powerful, that are created by the social context.

The first is collective or pluralistic ignorance: the failure to accurately perceive what is required in a situation because of over-reliance on social cues. In other words, we think that something is not an emergency, or action is not necessary, because when we look to others for guidance, we see that they are not taking action. This concept grew out of research by Latané and Darley (1968) on the "bystander effect": the fact that people often fail to provide help when they witness a situation in which help is needed. In a series of studies, Latané and Darley showed that people were more likely to help in an emergency, such as when smoke issued into a room or someone was apparently having an epileptic seizure, when they were alone rather than when they were in the presence of others. The researchers interpreted this as indicating that we look to others for cues about how to act, and what behavior is called for - is it an emergency? We are reluctant to deviate from a norm of inaction for fear of looking foolish. Collective ignorance refers to the failure of a group to accurately interpret the situation. Importantly, this phenomenon does not require that any individual tries to avoid acting, or to dissuade others from acting. Instead, the phenomenon emerges from the fact that everyone looks to everyone else, waiting for someone else to act first.

With regard to environmental problems, most people, at least in developed nations, have heard about the potential issues. But they look to their friends and their immediate social context, and see that most people do not appear alarmed and have not significantly changed their behavior. There may even be some stigma attached to those who have taken action, who are labelled as "hippies" or "extremists". So the typical person concludes that action, particularly radical action, is not called for and may even be socially sanctioned. The result is that most people reside in a state of collective ignorance about the scale of the problem and the changes that are required.

The second social barrier results when attitudes about environmental problems become associated with particular social groupings, so that people in one social group are expected to have a certain attitude toward the environment, and people in a different social group are expected to have a different attitude. Because social identity is so important, people adopt behaviors and attitudes that signal their identities, even when they actually have no real opinion or the attitudes are not consistent with their real beliefs and values. This has clearly happened with political parties, most strongly in the United States but also in 
a number of other countries around the world: parties on the political left call attention to environmental problems, while parties on the political right ignore them and in some cases deny their very existence. For example, US President Donald Trump has repeatedly called climate change a hoax.

There are several reasons why support for action to address environmental problems is more strongly associated with the political left than the political right. For one, conservative parties typically reject government interference in markets, which environmentalists typically advocate. At a more subtle level, conservatives tend to endorse slightly different values - such as respect for authority, and loyalty - than do liberals, who prioritize care and fairness. Research has found that environmental appeals often highlight "liberal" values such as care for the Earth; when appeals are reframed to emphasize "conservative" values, they get more support from the left. Finally, Al Gore was the opponent of the Republican presidential candidate George W. Bush in a fiercely contested and controversial race for the US presidency. Al Gore, founder of the Alliance for Climate Protection, also received a Nobel Prize for his efforts to communicate about climate change. For political reasons, many Republicans rejected not only Al Gore but also everything he was associated with. However, it is important to recognize that the link between political party and environmental concern is not inevitable. Many policies for environmental protection have been proposed and implemented by figures on the political right, in countries around the world. Patriotism, stewardship and fiscal responsibility, values that are championed by conservatives, can also be used to generate arguments for sustainability.

Interestingly, social polarization over environmental protection can also occur along class lines. Environmentalists are sometimes accused of being "elitists" who have no concern for the poor and working-class members of society; their policies are described (sometimes accurately) as increasing the financial hardship of those who are already struggling. This is illustrated with one of the slogans produced by the mouvement des gilets jaunes (yellow vests movement) in France when protesting against a projected carbon tax: Pour les élites: la peur de la fin du monde. Pour nous: la peur des fins de mois (For the elites: fear of the end of the world. For us: fear of the end of the month [when the money runs out]). However the social divisions run, the linkage between social identity and environmental attitudes forces one group to represent the opposition to environmental action, and characterizing the situation as "us vs them" makes it more difficult to work together as a society to come up with solutions. 


\section{MOTIVATING BEHAVIOR}

Identifying the barriers to behavior helps to identify the ways to overcome them, and points toward opposing forces that can motivate environmentally protective action. I will discuss the sources of motivation in three categories, though many examples may be impossible to neatly categorize into just one of these areas. First, and often easiest to address, are aspects of the physical environment. Second, there are important social factors. Finally, there are individual characteristics that may be fostered or activated in order to motivate sustainable action.

\section{The Physical Environment}

Making changes in the physical environment is often the easiest, as well as the most effective, way to encourage more sustainable behavior. Because, as mentioned above, people often act without really thinking about what they are doing, they can be highly responsive to environmental cues and affordances the behaviors that are enabled by the physical context. So, for example, people are significantly more likely to do things that are easy: to bicycle if there are bicycle lanes, to buy an electric car if there are charging stations. They are more likely to recycle if recycling containers are clearly marked and easily accessible. The visibility of recycling containers also matters; they should be in a well-lit location. Even the structure of the recycling container affects people's recycling competence; in one study, containers with distinctively shaped lids (e.g., with a slit for paper in one and a round hole in another) led to less contamination of recycling compared to no lids. Potentially even more effective are structural changes that do not require people to think at all: motion sensor lights that go off automatically after people leave a room; low-flow showerheads that reduce water use; energy efficiency standards, such as for automobiles or appliances, that are enacted at the level of product design rather than at the level of consumer choice.

A possible drawback to these approaches can be if they arouse resentment. People don't like to feel that their behavior is being controlled by others, and if the structural constraints on their behavior are too obvious people may exert effort to regain personal control by acting less sustainably. So, for example, some people have adopted workarounds that allow them to increase the pressure in their showers. Another drawback is that modifications of the physical infrastructure may seem to absolve people of personal responsibility, so that they think that they don't have to worry about environmental sustainability because (for example) the government is taking care of it. Although changing features of the physical environment to encourage sustainable behavior is an 
important approach, it must be done sensitively and should not be the only way of promoting environmental concern.

Another way of modifying the physical environment, which makes more allowance for good individual intentions, is to give people feedback about their behavior and its impact. People may care about the environment but be unaware of the ways in which their actions are having a negative impact. Or they may want to reduce their energy use but have no idea how much energy they are currently using, and how different behavioral changes affect their overall usage. Individualized feedback, such as from energy or water meters, can give people the information they need to gauge their own efficiency. Many energy companies in the United States have increased their emphasis on providing customers with the ability to track their own energy usage from month to month. Some automobiles, too, allow drivers not only to see how much gas they have but to track how their fuel efficiency changes from moment to moment under different driving conditions. This type of feedback can then be paired with suggestions - for example, from the energy company or the automobile maker - about how efficiency could be improved with some simple behavioral changes, such as insulated shades for the house and proper tire inflation for the car.

Suggestions for sustainable behavior seem like a good idea, but they have to be framed in the right way (Markowitz \& Guckian, 2018). Many well-intentioned messages are ignored. People are constantly bombarded with information, so messages need to stand out. They also need to have the right content. Information about environmental threats is typically not what is needed to get people to behave in a more sustainable way. The messages need to attract attention, perhaps through visual interest, and by utilizing interesting content that personalizes the issue and provides an emotionally compelling narrative. They may also need to provide information, but the most useful information may be descriptions of how to change behavior rather than why. People typically know that the natural environment is endangered, but they frequently don't know what they can do about it.

Messages can even inadvertently backfire - for example, by eliciting the resistance to behavioral control that was described above, or by suggesting that unsustainable behavior is normative. Some pro-environmental messages include a description of an unsustainable behavior choice that many people make: environments are degraded because of the large number of people who litter, or due to the unsustainable food choices that constitute the typical diet. Although these messages are designed to illustrate the need for more sustainable behavior, they also suggest that it is normal to behave unsustainably. Researchers have found that such messages may actually encourage people to make the unsustainable choice, presumably because "everyone is doing it". 


\section{The Social Environment}

As the previous example illustrates, and as discussed earlier, the social environment exerts an extremely powerful influence on people's behavior. Fortunately, this influence can work to encourage as well as discourage sustainability. When sustainability is seen as socially valued, the desire to impress others can motivate people to demonstrate their pro-environmental credentials. A number of studies have shown that people are more likely to purchase "green" rather than conventional products when they care what other people think about them, and when they think that other people will see and value their green choices (Griskevicius, Tybur \& Van den Bergh, 2010). Even more powerful is the simple knowledge that other people are behaving in sustainable ways. People are more likely to install solar panels if their neighbors have them, and more likely to engage in sustainable agricultural practices if their neighbors engage in them. Returning to the example of the energy company, research has shown that providing people with feedback not only about their own energy use but also about the energy use of their neighbors tends to reduce the energy use of people who are using more than others (Schultz et al., 2007).

This raises the question, what about those who are using less energy than their neighbors? Does giving them this feedback lead them to increase their energy use? Yes, but this tendency can be mitigated. There are two types of social norms, descriptive and prescriptive: descriptive norms describe what other people do, and prescriptive norms describe what other people value or think should be done. Both can be influential. When people see that others are using less energy, the descriptive and prescriptive norms align. When people see that others are using more energy, the descriptive norm suggests using more, and on average people do increase their energy use. But if, when people see that others are using more energy, they are reminded of the prescriptive norm - the desirability of using less energy - they do not increase their own usage.

A more direct way in which the social environment can encourage behavior is when people form groups. Regardless of the primary reason for joining a group, group membership has several potential benefits: not only does it increase the ability to effect change, it also provides social benefits that include companionship and a feeling of belonging, a group identity, a sense of meaning and purpose, and the positive emotional experiences that accompany shared group activities. Just consider the shared celebrations that follow successful group activism. In order to be happy, people have a common set of core needs, including the need for self-esteem, for belonging, and for a sense of meaning; all of these have the potential to be met by group engagement. In a virtuous cycle, these shared group experiences contribute to a group identity that then strengthens engagement with the group. And when people commit to 
a group, they are more strongly affected by group behavioral norms. If people join pro-environmental groups, whether they engage in political activism, direct environmental action (like community clean-ups), or simply conversation about shared environmental interests, the norms that emerge are likely to promote more sustainable behavior.

Environmental problems are fundamentally collective problems: individual behavior will rarely lead to meaningful change, and environmental action is usually directed toward benefiting the collective rather than individual self-interest. That means it is useful to consider the environmental problems as examples of public goods dilemmas: cases in which individuals, acting in their own self-interest, fail to preserve a public good and thus lead to a more negative outcome for everyone including themselves. Each fisher, for example, may be motivated to catch as many fish as possible, but if everyone behaves that way, the fish stock will collapse and no one will have enough. Each individual may be motivated to pollute the air without paying the cost of clean-up but if everyone does this the air will become toxic to all. There are solutions to such dilemmas, often involving some form of regulation, but individuals are most likely to act on behalf of the collective when they trust other members of the group, feel that they have shared goals, and are able to communicate with each other. A strong group identity - which could include a national identity is likely to encourage this orientation toward collective well-being.

\section{Individual Characteristics}

It is clearly the case that some people are more environmentally engaged than others: some people are climate champions, raising the bar and showing others the kind of behaviors that are possible and necessary. What explains these outliers? No single individual can be reduced to a simple formula, but three personal characteristics are important predictors of environmental activism. One is simply environmental concern, which is greater among some people than others. A second is a strong sense of moral responsibility: the need to act in a way that is consistent with one's values. And a third might be described as the confidence to take action that deviates from the norm, even when the consequences are not fully known.

There is a great deal of research on environmental concern. Not surprisingly, people who value the environment are more concerned about threats to the environment. Value for the environment is associated with early significant experiences in nature; although it has been argued that people have an inherent tendency to enjoy nature, that tendency needs to be nurtured (Chawla, 1999). People who are unfamiliar with natural settings may find them uncomfortable or frightening, since they don't know what to expect or how to behave in those environments. Although adults can learn to love nature, experiences tend to 
be particularly influential for young children, who are still developing a sense of themselves and learning about their own abilities. Especially when in the company of significant adults, who can make the experience more meaningful and manageable for the child, experiences in natural environments can lead children to construct a self-identity that acknowledges interdependence with the natural world. This linking of identity with environmental issues makes environmental topics more personally relevant and is associated with pro-environmental behavior later in life.

Liking nature is important, but most people like nature. Taking action on behalf of the natural environment also requires a sense of personal responsibility. This, too, is associated with early experience. Although it is impossible to perfectly predict who will become an activist, people who are exposed to role models - often a parent - who demonstrate the importance of acting in support of one's beliefs, are more likely to internalize that sense of obligation to stand up for what they believe to be right. The role model doesn't have to be an environmental activist; it is the need to take action in support of one's beliefs that is learned by imitating others. However, role models are not the only influence on people's tendency to stand up for their beliefs. The personality trait of conscientiousness is also implicated, and research suggests that personality is in part affected by genetics.

Finally, activism may require a willingness to take actions that challenge the status quo. Doing what everyone else does is safe; even if it is the wrong action, there is usually no social risk in doing what others are already doing. Doing something different entails the possibility not only of social disapproval, but also of other negative consequences, unforeseen because the behavior is novel. Thus finding, and belonging to, a group of people who support environmental engagement is likely to increase pro-environmental behavior by reducing those risks. However, there are environmental activists who are willing to defy social norms entirely. Such activism is likely to be associated with a perception of personal efficacy, or the belief that one can effectively accomplish what one sets out to do.

\section{CONCLUSION}

We are facing unprecedented environmental changes. Individual action is necessary, not only because individual and household consumption of environmental resources accounts for a significant proportion of environmental impacts (think about private car use, discretionary air travel, and meat eating), but also because individuals' attitudinal support and behavioral adoption is necessary for public policies to be successfully implemented. Psychological research can help to understand people's responses - or lack of responses - to these environmental crises, and this understanding can encourage messaging 
and behavioral interventions that promote sustainability (Clayton \& Manning, 2018).

In some ways, the inadequate response to the environmental crisis is understandable. People are not good at planning for the future, especially when it is uncertain. There are always more immediate concerns to capture attention. Social dynamics as well as inertia make it easy to continue with the status quo. But there is increasing recognition of the fundamental connections between human and environmental health, and the need to protect the environment is becoming increasingly clear. Most people agree that protecting the environment has an ethical component. Nearly everyone acknowledges that it is necessary for our well-being.

There have always been people who stand out from the crowd, whether it be the scientists who pointed out the possible impact of carbon emissions on climate back in the early twentieth century, the inventors and entrepreneurs who are committed to finding new ways of doing things, or the activists who persist in drawing attention to a message that people do not want to hear. What we need to do now is allow these outliers to create new norms: behavioral, attentional, but also moral. Just as there can be tipping points in environmental systems, a social tipping point can occur when a small group of people demonstrate the possibility of a societal transition.

\section{REFERENCES}

Chawla, L. (1999). Life paths into effective environmental action. The Journal of Environmental Education, 31(1), 15-26.

Clayton, S., \& Manning, C. (Eds.) (2018). Psychology and climate change: human perceptions, impacts, and responses. San Diego, CA: Elsevier.

Clayton, S., \& Myers, G. (2015). Conservation psychology: understanding and promoting human care for nature (2nd ed.). Oxford: Wiley-Blackwell.

Griskevicius, V., Tybur, J.M., \& Van den Bergh, B. (2010). Going green to be seen: status, reputation, and conspicuous conservation. Journal of Personality and Social Psychology, 98(3), 392-404.

Latané, B., \& Darley, J.M. (1968). Group inhibition of bystander intervention in emergencies. Journal of Personality and Social Psychology, 10(3), 215-21.

Markowitz, E.M., \& Guckian, M.L. (2018). Climate change communication: challenges, insights, and opportunities. In S. Clayton \& C. Manning (Eds.), Psychology and climate change (pp. 35-63). London/San Diego, CA: Academic Press.

Schultz, P.W., Nolan, J.M., \& Cialdini, R.B. et al. (2007). The constructive, destructive, and reconstructive power of social norms. Psychological Science, 18(5), 429-34. 